\title{
Unilateral renal cystic disease in the right kidney
}

\author{
Eun Hui Bae, Young-Hwan Hwang, Soo Wan Kim
}

Departments of Internal Medicine, Chonnam National University Medical School, Gwangju, and Department of Internal Medicine, Eulji General Hospital, Seoul, Korea

A 51-year-old man was referred from oncology department with incidental detection of unilateral multiple renal cysts on computed tomography (CT) during evaluation of colon cancer (Figure-1). Abdominal CT revealed enlarged right kidney with variable-sized round, well-marginated multiple cysts without capsule formation or solid content, while the left kidney was normal. Family history was negative for kidney disease. Ultrasound imaging of the parents, five adult siblings, one son and two daughters showed normal kidneys. He received chemotherapy with 5-flurouracil plus leucovorin after laparoscopic right hemicolectomy for colon cancer. The relevant laboratory data were as follows: white blood cell count, 7000/mm3; hemoglobin level, $15.9 \mathrm{~g} / \mathrm{dL}$; platelet count, 174,000/mm3; blood urea nitrogen level, $15.5 \mathrm{mg} / \mathrm{dL}$; creatinine level, $0.8 \mathrm{mg} / \mathrm{dL}$ and no proteinuria or hematuria. We did not introduce specific therapy for the unilateral cyst and follow-up was made with magnetic resonance image (MRI) six month after hemicolectomy. The exam showed numerous cysts in the right kidney with no changes according to previous CT (Figure-2).

This patient has unilateral renal cystic disease (URCD), a rare entity characterized by multiple cysts in one kidney or a portion of one

Figure 1 - Preoperative axial (A) and coronal scan (B, C) of abdominal CT showing multiple cysts in the right kidney.
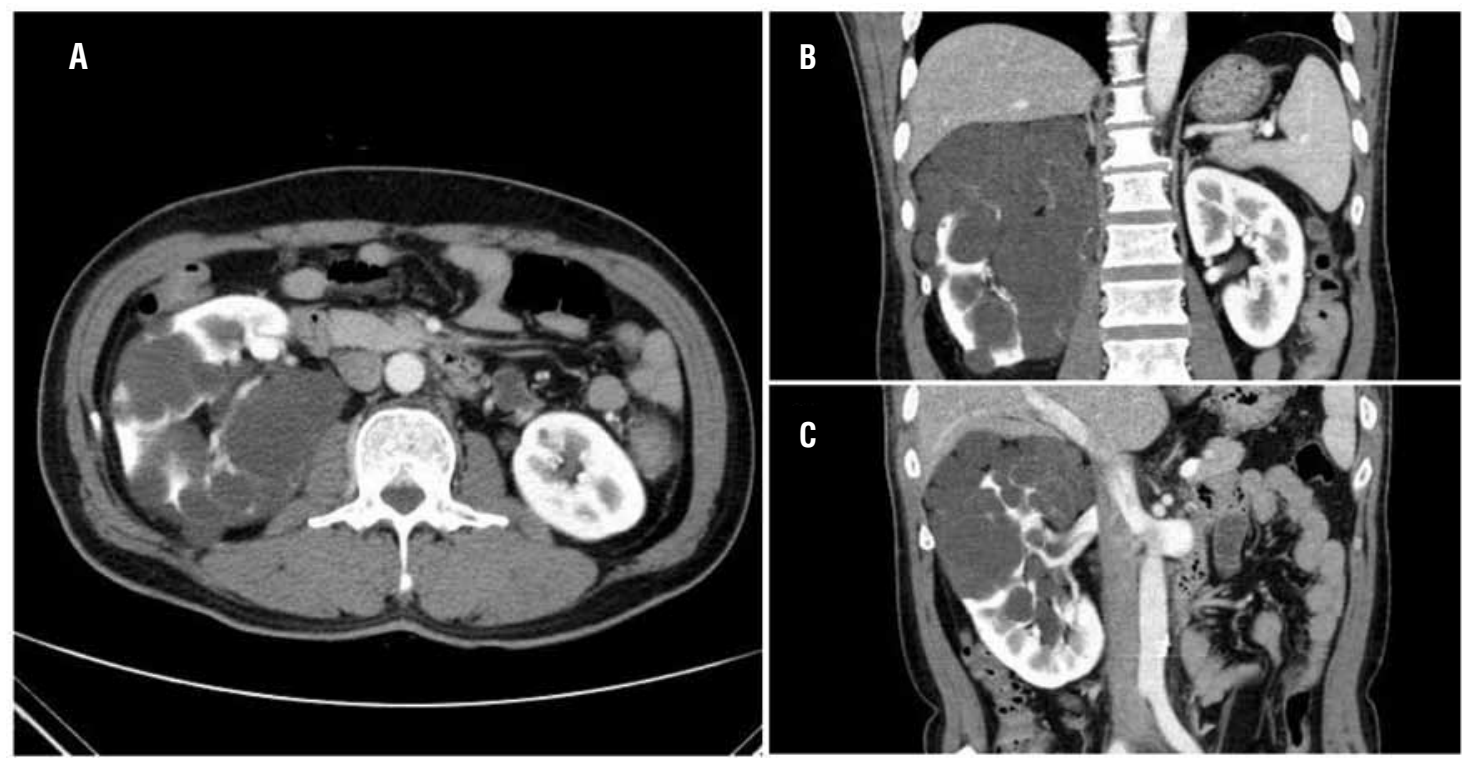
Figure 2 - Postoperative axial (A) and coronal scan (B) of the kidney MRI (T2 weighted image) showing multiple cysts in the right kidney.
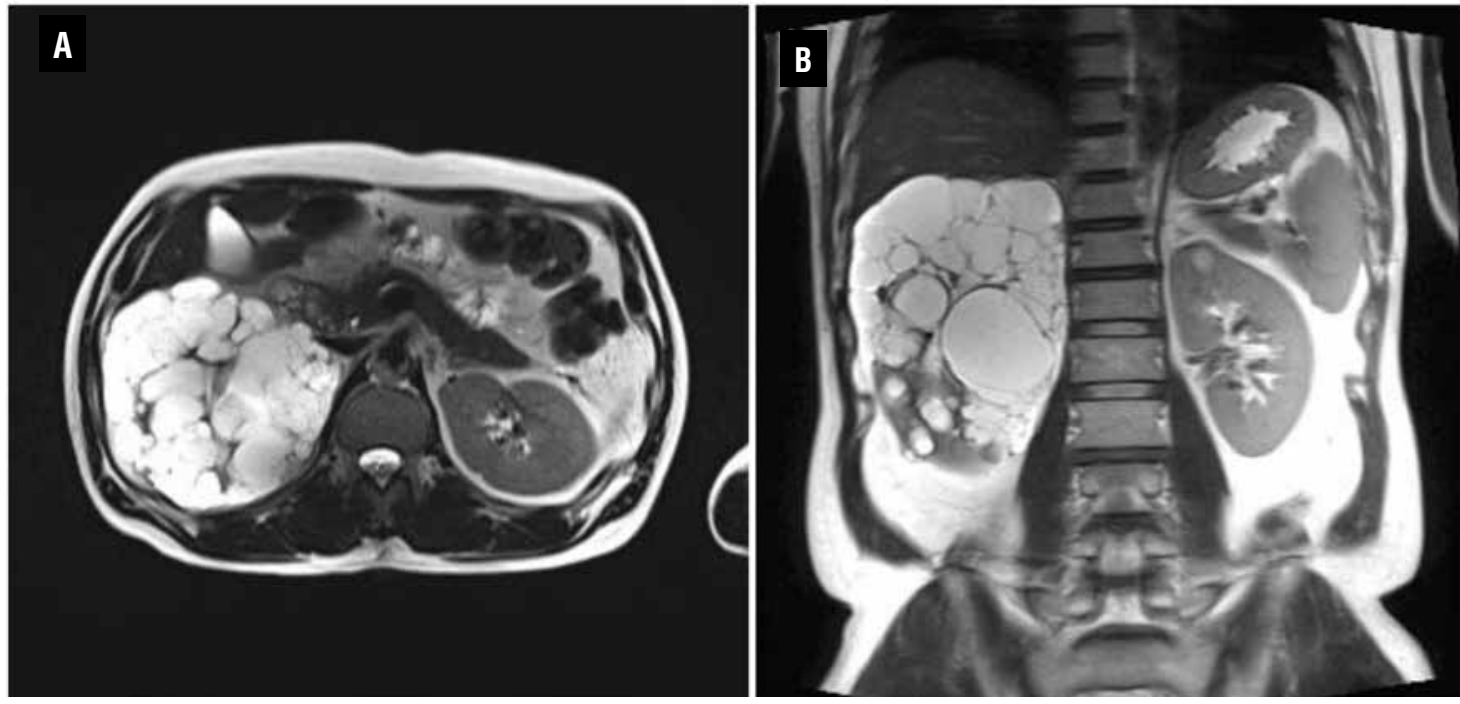

kidney. The clinical importance of URCD is to make a differential diagnosis of such abnormalities including multilocular cystic nephroma, cystic partially differentiated Wilms' tumor, segmental cystic dysplasia, and atypical presentation of polycystic kidney disease such as asymmetric evolution and mosaicism $(1,2)$. The pathogenesis of this cystic renal disease is unknown. Since there is a morphological similarity of this cystic change to autosomal dominant polycystic kidney disease (ADPKD), it is speculated that pathogenesis is similar (3). The gross and microscopic features are indistinguishable from ADPKD, and patients may present with hematuria, pain, or a flank mass (4). However, it can be differentiated from ADPKD by its unilateral localization, negative family history, no progression to chronic renal insufficiency, and no extrarenal manifestation. Cystic adenosarcoma of the kidney can present in a very similar way and it can be differentiated by positive reaction to epithelial membrane antigen (EMA), vimentin and transducin-like enhancer protein 1 (TLE1), and CD99 (5). Most importantly, it must be differentiated against segmental cystic dysplastic disease. In case of URCD, collecting sys- tem should be shown continuously though distorted collecting system. Otherwise it would lean to segmental cystic dysplastic disease $(6,7)$. The collecting system of this patient was continuous (Figure-1C).

URCD is a stable disease and patients can be followed up by imaging techniques (8). In conclusion, unilateral cystic disease of kidney is a rare cystic disease of the kidney diagnosed by imaging techniques and requires nephrectomy only when suspicion of malignancy is strong.

\section{REFERENCES}

1. Reed B, Nobakht E, Dadgar S, Bekheirnia MR, Masoumi A, Belibi $F$, et al.: Renal ultrasonographic evaluation in children at risk of autosomal dominant polycystic kidney disease. Am J Kidney Dis. 2010; 56: 50-6.

2. Connor A, Lunt PW, Dolling C, Patel Y, Meredith AL, Gardner A, et al.: Mosaicism in autosomal dominant polycystic kidney disease revealed by genetic testing to enable living related renal transplantation. Am J Transplant. 2008; 8: 232-7.

3. Gouldesbrough DR, Fleming S: Unilateral and segmental localised polycystic kidney disease. J Clin Pathol. 1998; 51: 703-5. 
4. Hwang DY, Ahn C, Lee JG, Kim SH, Oh HY, Kim YY, et al.: Unilateral renal cystic disease in adults. Nephrol Dial Transplant. 1999; 14: 1999-2003.

5. Sameshima N, Marutsuka K, Tsukino H, Kamoto T, Kono S, Asada Y: So-called 'adenosarcoma' of the kidney a novel adult renal tumor with a cystic appearance. Pathol Int. 2011; 61: 313-8.
6. Clevert DA, Horng A, Staehler M, Haseke N, Stief C, Reiser M: Diagnostic algorithm in cystic renal masses. Urologe A. 2010; 49: 421-32.

7. Song C, Min GE, Song K, Kim JK, Hong B, Kim CS, et al.: Differential diagnosis of complex cystic renal mass using multiphase computerized tomography. J Urol. 2009; 181: 2446-50.

8. Slywotzky CM, Bosniak MA: Localized cystic disease of the kidney. AJR Am J Roentgenol. 2001; 176: 843-9.

\section{ARTICLE INFO}

Int Braz J Urol. 2013; 39: 435-7

Submitted for publication:

February 18, 2013

Accepted after revision:

March 12, 2013

Correspondence address:

Dr. Soo Wan Kim

Department of Internal Medicine, Chonnam National University Medical School Hakdong 8, Dongku, Gwangju 501-757, Korea

Fax : + 8262 225-8578

E-mail: skimw@chonnam.ac.kr 